\title{
New Food Development in the Age of Crisis Experiences from Italy and Romania
}

\author{
Codrin $\mathrm{Chiru}^{1}$ and Lina Chiru ${ }^{2}$ \\ ${ }^{1}$ The Bucharest Academy of Economic Studies, Faculty of Commerce, Bucharest, Romania \\ ${ }^{2}$ Politehnica University of Bucharest, Faculty of Applied Chemistry and Materials Science, \\ Bucharest, Romania
}

\begin{abstract}
In the last decade, many experts in nutrition and wellness have anticipated the key role of innovative foods in helping consumers to have a healthy lifestyle. This study analyzes a series of complex key drivers that influence the food business, taking into account experiences of agri-food producers from Italy and Romania. There have been identified a series of operational flows that slow down the development of this industry, mitigating the synergy among research and development (R\&D), sales and marketing functions. One of the findings of this research is that the identified communication barriers among food technologists/engineers and marketing experts could evolve into business unethical approaches (e.g. deceptive packaging, creation of "false needs", etc.) that could mislead consumers, hinder their knowledge and freedom of choice, thus driving health risks. A smooth integration of traditional values in the food design is essential to assure the proper balance between scientific research, cultural background and values in order to enhance consumers' health. This paper concludes that food companies should integrate local/traditional recipes into their new products to assure superior communication and consumer understanding of the newly discovered bio-active ingredients and to drive consumers' acceptance, positive attitudes and receptivity towards the new aliments.
\end{abstract}

Keywords: Traditional food, Bio-active ingredients, Consumer health, Innovation management.

\section{Introduction}

The fast-pace developments in genomics (gene analysis), transcriptomics (gene expression analysis), proteomics (large-scale study of proteins), metabolomics (metabolites profiling) have created the premises for adapting people's nutrition to the actual dynamic lifestyle. This process is centered on food design based on biological needs and consumers' superior education and knowledge to choose and to introduce new foods in their diet (Shepherd, 1990). Therefore, the constant change of some of consumers' nutrition items may be the sources of progress in their lifestyle. Among the factors that generate change in the daily diet, the most important are: evolution of lifestyle and work, with consequences for food habits, the increasing level of the national food cultures, leading to more accurate understanding of needs, producers' desire to provide new gastronomic satisfactions, to communicate a distinctive message through food and menus (Coveney, 2005). Reconsidering the food style is an objective process required for each individual, creating improved and powerful

Copyright (C) 2012 Codrin Chiru and Lina Chiru. This is an open access article distributed under the Creative Commons Attribution License unported 3.0, which permits unrestricted use, distribution, and reproduction in any medium, provided that original work is properly cited. Contact author: Codrin Chiru E-mail: icchiru@yahoo.com 
solutions beyond those used previously. Therefore, a rethinking process should be accomplished by taking into account the culinary traditions and habits of each consumer's group.

The above presented trends have emerged into a new phenomenon, called "scientification" of eating (Niva, 2007). This concept is the outcome of the complex process that includes the mix of various scientific fields, such as: nutrition, dietology, medicine, pharmacology, bio-chemistry, gastronomy, food technology, marketing, business administration, etc.

The European single market has created new business opportunities for companies from the EU15. They have been successfully selling their products in the new member states (i.e. Bulgaria, Czech Republic, Hungary, Poland, Romania, Slovakia and Slovenia), broadening the negative quantum of the trade balances of the latter. The Romanian food market, which has continuously been under a negative trend after 1989, needs special reorganization measures within the actual context of the EU economy. Moreover, it is considered that the common agricultural policy (CAP) mechanisms do not stimulate this industry in general, being limited to measures focused on helping the food producers associations. Structural changes in the EU economy that have occurred in recent years have led to the emergence of frequent market failures that have generated high prices, difficulties of the Eastern European farmers to sell their products, the apparition of supplementary entities in the commercial chain and many cases of unfair competition. All these distortions came on top of a range of economic weaknesses of the Romanian farmers, such as their incapacity to develop sustainable relations with the modern trade, low productivity in the rural areas and their inability to develop a coherent marketing strategy. Poor life quality in the rural areas (kept down by weak education, health and financial systems, that are well below national average), drive the emigration to urban areas or abroad. Romania's privatization and liberalization efforts and its further integration in the transnational structures (in particular WTO and the EU) during the past two decades were followed by a wave of progressive investments made by several international food companies. This trend, combined with increasing urbanization, superior purchasing power and shifts in consumers' preferences have led to a dramatic growth of the food business (including producing, processing and marketing of foods) in a far more complex, multifaceted technological environment. Food industry generated more and more new requirements in industry standards, including food quality and safety, traceability and certification.

\section{Literature Review}

The actual business decision makers are faced with an increased pressure generated by various convergent trends, such as higher energy costs, more demanding legislation aimed to increase state incomes and to reduce pollution, corporate trust erosion, consumers' higher awareness and education levels (Willard, 2005). Facing with these new realities, companies are changing their strategic orientation from classical "business recipes" towards more structured approaches based on innovative and complex decisional processes (Ehrenberg, 2000). A new and much more complex business orientation has been developed as a complementary system of the classical management methods and tools, acting like an enclosing circle to describe a new horizon of today emerging society towards sustainable development in which companies find their own creative ways to reach their goals (Broman et al. 2000).

In the context of international economic crisis, the macroeconomic austerity programs mitigated the capacity of the developing countries to implement sustainable agriculture strategies, therefore their domestic companies had been failing to produce competitive products. Moreover, in the case of agri-food business, the lack of 
involvement of the technological research and the old technical heritage of the former communist countries in Europe have caused not only an overall decrease in competitiveness, but also deepened the differences between East and West. (DehnenSchmutz et al, 2010). In this context of the increasing gap between local and international companies in favor of the latter, a few recent studies developed a series of new management systems applied in the agro-food industry, which were created mainly to help the small and medium sized enterprises to cope with the challenges that are coming from the modern retail, that requires large suppliers, has a strategic emphasis on quality standards, large marketing campaigns, low costs and sound supply chain management. (Duffy and Fearne, 2007).

In the last decade, companies across the world that are doing business in the agrifood sector have been increasingly focused on the success of the functional foods. Although not yet (finally) defined by the EU legislation, functional foods have been characterized in various ways, like foods marketed as health enhancers or reducing the risk of disease or a new variety of foods that promise targeted improvement in physiological functions in the body (Diplock et al., 1999). Functional foods in general, through their particular bio-active components, are directly connected with a series of well-defined physiological effects that drive noticeable health enhancements. Therefore, to become a commercial asset, this category needs scientifically proved substantiation about the health effect, a process that requires substantial research and development (R\&D) efforts.

The industrial production of functional foods - that often requires modern food technology since a constituent needs to be added, removed or modified - increases the risk that this category will be perceived as less natural than conventional products and are thus avoided by those who value naturalness in food choices (Frewer et al, 2003). Studies made on of various types of functional foods concluded that consumers usually perceive functional foods and healthy eating from various perspectives: focus on their daily diet and dichotomies such as healthiness vs. functionality of foods, health vs. pleasure eating dilemma or the technological risks (Niva, 2007). It is widely recognized that the market success of the newly discovered foods depends on consumers' acceptance of the products as part of their daily diet. (Annunziata and Vecchio, 2011) This diversity of perspectives reveals that interpretations of functional foods and healthy eating are linked with uncertainties related to the scientific knowledge. Little attention is given to food choices in the daily diet and recurrent health risks. There is an increasing gap between food and health, a complex link, especially in the case of humans' omnivore diet. (Lappalainen, et al, 2008; Coveney, 2005) Also, researchers are focused more on the assessment of the potential hazard of food in the short term without making reference to the possibility that food could become dangerous on a longterm range. (Richardson et al, 2004) It is given very little emphasis on educating "food preferences" in the early years of children development, which underpins food repertoire of every individual. (Margetts et al., 1997; Pravsta et. al, 2010)

\section{Methodology}

This study aims at investigating the following areas of expertise within the adoption of innovative foods:

1) The complex relation between $R \& D$ and marketing in the agri-food business regarded as the main innovation engine together with the occurred malfunctions and the mediation process induced by the complexity of the present social and economic landscape. There were targeted various collaboration issues between marketing and R\&D occurred in both large/multinational and small and medium sized companies together with 
their possible impact on consumers' health.

2) The different strategic approaches of the companies from Italy and Romania and the assessment of the related effects on companies' performance, local marketing initiatives and new products. It was considered the case of the functional foods, taking into account the novelty, dynamics and potential scale of this segment.

To undertake the above mentioned goals, a qualitative research was developed and implemented with sales-marketing and R\&D teams from 47 food producers and retailers (22 from Romania and 25 from Italy). The companies' sizes varied from 24 to $500+$ employees, part of them being transnational (multinational corporations). No exact information on the total number of companies that produce innovative/functional foods was available, so neither a random sample nor a quota sample was possible. There were done interviews with the top/middle managers from sales, marketing, R\&D and production departments. E-mail questionnaires were administered with the personnel who could not be directly contacted or was too far for visiting. Each interview/questionnaire consisted in 20 closed questions, with complete system of choice and 5 additional open questions. The survey was done in different locations from Romania and Italy in the period January-September 2011. Respondents were asked to rank factors according to their vision of business. A parametric classification method was used (on a scale from 1 to 15,1 - the least important, 15 - the most important factor). Based on comparative analysis performed in the food producers in Romania and Italy were tested various business strategic options that managers / key employees of those companies would prefer to further undertake. There were investigated the opportunities and key factors that could lead to a smooth development of the food business in general and of innovative/functional foods in particular.

\section{Results \& Discussion}

This study is based on information obtained from 47 food retail and producing companies from Romania and Italy (as explained in the methodology). We identified a number of key elements (key drivers), that influence the business performance and innovation management in the food industry. Based on comparative analysis performed in Romania and Italy we tested various business strategic opportunities that managers from both countries would prefer to follow. The figure below shows the identified business options (strategic profiles), based on the answers received from the Italian companies (marked in blue) and Romanian companies (marked in red).

There were identified substantial differences in terms of attracting EU funds, which received more attention from the Romanian companies. The Romanian respondents also showed a higher need for stricter regulations in the agri-food production. The Italian companies proved to be more interested in the availability and costs of new technologies (including patents and licenses) and also put more emphasis on the coordination of producers' associations. Meanwhile, Romanian producers looked very keen on promoting and facilitating new business partnerships. Similarities were on consumers' side: consumers' willingness to buy bio/eco- food, consumers' propensity to buy national/domestic products or concerns regarding traditions had similar levels. A notable difference was observed in consumers' willingness to buy food that enhances health, Italians looked more concerned to adopt a healthy diet. 


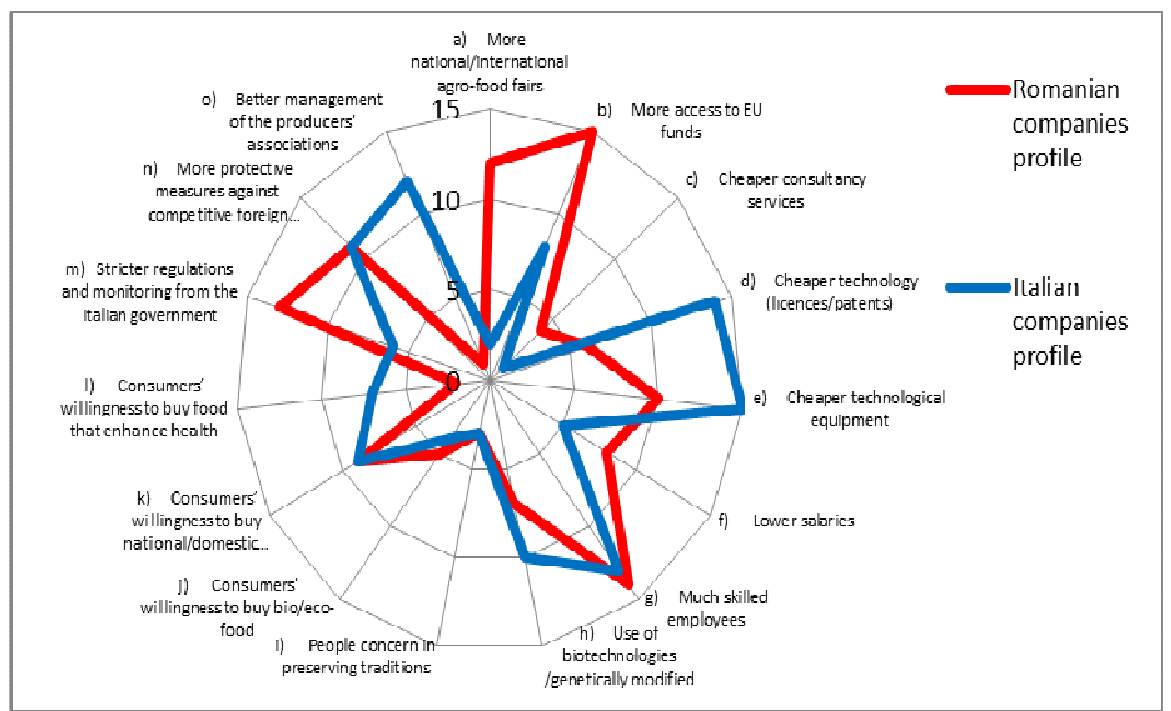

Fig 1. Comparative Analysis of the Food Business Drivers - Italian and Romanian Companies

The results revealed that Romanian managers form two distinct clusters: 1) employees from multinational companies who possess different mind-sets and perceptions in terms of product strategy, marketing research, testing and commercialization and 2) the employees working in small or medium sized Romanian owned companies. This differentiation was showed in past research (Chiru, 2009; 2011). While the "traditional thinking" is that the marketing strategy is the exclusive tasks of the marketing/commercial department, the employees from the analyzed companies have a different vision, usually perceiving these processes holistically. Questioned about their involvement in the products' marketization they indicated a much more concern and time allocated for the marketing processes. It was also observed an increase of the R\&D staff involvement inversely with age. Reasons of this different behavior are:

- The Romanian technical staff/researchers are very used only to execute and also they have a very limited knowledge of the product marketization;

- Most of the international food producers have not deployed full $R \& D$ facilities in
- Romania, the majority of the products' recipes being created and developed abroad without any input from the local staff;

In both countries the information flow between marketing and R\&D employees has several issues, the most frequent are:

- Poor / tardive information between R\&D and marketing teams;

- Insufficient feedback on products' quality and technical characteristics among R\&D staff;

- Lack of feedback from the marketing employees regarding clients/consumers experiences with the product, habits and practices.

The weak integration and knowledge transfer between these two functions create several shortcomings for the Romanian marketers working in several large companies, the most relevant being:

- A limited understanding of the technical processes (especially chemical and 
biological operations) that are part of the various production stages;

- A limited economical assessment of the use of ingredients/compounds that could harm consumers' health (Ward et al. 2000; Brambilla and Martelli, 2007) like: various alimentary additives, alimentary preservatives, dyes, nitrates and nitrites, etc.;

- An underestimated long term impact of food additives on consumer health.

This study also revealed the heterogeneous character of activities/phases like: new product strategy elaboration, new ideas and screening, concept development and testing, product development, test marketing and commercialization. There were identified different working philosophies at departmental level. Marketing efforts are usually focused on stimulating demand for commercial products and services. But demand creation is only a part of the marketing activity. A broader strategic view is that marketing should completely lead the entire process in a company focused on value creation, also known as "value delivery sequence" approach (Kotler, 1999, 2000). The product development phase, which is very important in the food industry, includes the value positioning process, a key marketing concept. At this stage the dialogue between marketing and research becomes crucial. The R\&D efforts are usually targeted to design competitive products according to the company strategy. As a primary source for new technologies and knowledge, R\&D specialists have to shape and manage the market trends, to understand customer evolution and drive the social function of technology. (Rao, 2005)

Most of the analyzed companies use external recipes and marketing concepts, developed by large /global suppliers. This leads to little involvement from their research departments. Therefore their internalized tasks are mostly recipes adaptation, production process monitoring, safety and quality assurance. For Romanian small and medium sized food producers there is little chance to develop new specific/dedicated recipes. Therefore, some new (global) trends like dietary diversification, anti-aging or personalized nutrition are not expected to emerge very soon in Romania.

Low technological capabilities have been revealed as a major limit in both countries. Most of the investigated producers have an average laboratory for monitoring products quality and food safety assessment. Usually, they are under the direct supervision and hierarchical subordination of local production managers who have responsibilities related to: inventory control, production scheduling, equipment maintenance, calibration, factory warehousing, quality control and food safety assessment. Since the production managers have different responsibility areas than marketing and sales counterparts, the relation between Marketing and R\&D can be cross-departmental only. Therefore the R\&D activities become more operational, focused on daily monitoring and supervision of the technical processes rather than dedicated to innovation and new product development (Chiru, 2009; 2011).

Internal communication flows and unharmonized priorities are the main issues in the collaboration process between marketing and $R \& D$ in many companies from the sample. Judgmentally, this status triggered a non-innovative character of the Romanian food market, most of the existing products and their marketing concepts being more or less replicas of commercial hits from abroad. Moreover, some sensitive and elaborated technical details regarding food production processes are known only by a very limited number of employees due to the recipes protection policies of the companies (Chiru, 2009).

This lack of cohesion is deepened by other issues revealed by this research: 
- The lack of market approach of technical/R\&D specialists; therefore a high number of research activities and projects are not economically feasible;

- Food technologists are inclined to underestimate their social and ethical role being usually unaware about their key position in the entire commercialization process (Chiru, 2011), including the responsibility of using natural ingredients or preserving tradition and cultural heritage.

One of the main strengths of companies that have cross-country activities derives from their capacity to build competitive advantage through knowledge transfer across borders. One of the main points of this study is that multinational enterprises present in Romania are insufficiently using the complex mix of location bound and non-location bound specific advantages. According to Rugman and Verbeke (2008), the principal drivers of the corporate specific advantages are

- The geographic distribution of plants across the world;

- The presence of regional components in companies' strategy and structure;

- The centralized decision making combined with local market adaptation.

The majority of the interviewed experts mentioned that are many similarities between several newly developed functional foods (having various raw ingredients like nettles, maize, carrots or grapes) and some Romanian traditional recipes, a fact that was revealed in previous research (Stroia and Chiru, 2010). Therefore food producers from Romania could use the local gastronomic repertoire as a scientific platform to further design new functional foods. Moreover, some important attitude and decision factors (i.e. familiarity and heritage) could be assigned to the newly designed foods in order to facilitate their market penetration. The functional reengineering of the traditional food could become a future fast developing domain in the agri-food business, capable to provide long term solutions to the actual global

The interviews also measured the innovation barriers/challenges, according to the framework proposed in a previous study (Tylecote and Ramirez, 2006); the main barriers/challenges for the companies from both countries are: 1) the novelty of innovation (how far does a product or process of innovation requires radically new ways of organizing its development or production, radically new technologies, and/or radically new markets or selling methods) 2) the need for reconfiguration (to what extent does the organization of the firm need to be reconfigured in order to succeed in innovation), 3) the visibility of innovation (how easy is it for the staff not closely involved in managing the development of a new product or process, to judge what resources are being devoted to it, and how efficiently) and 4) the 'appropriability' of innovation (how the firm can ensure straightforwardly, for example, by patents). The majority of respondents marked the visibility of innovation ( $3^{\text {rd }}$ challenge) as the most critical one, being one of the main factors that determine delays and performance loss in the food industry.

Some other drivers that could influence the knowledge transfer between R\&D and marketing and also the overall company performance occurred from this study: the low level of industry-wide expertise (Romania), the degree of employee's inclusion through shareholdings and the pressure for shareholder value (Italy). We found out that in general, the marketing employees were much more concerned and involved in rising the value for shareholders (especially through driving the return on investment (ROI)) while the R\&D employees were much more concerned about the new technologies, but unaware how to use them in order to increase the shareholder value. 


\section{Conclusions}

Food companies, in order to be sustainable, need to undertake a mixed/balanced approach of global and local/regional strategies. New foods business, being exploratory and having a high degree of novelty, seems to be suitable for the "balanced" structural organization model (i.e. structural separation, parallel structures) that is able to mediate conflicting functions (i.e. marketing and R\&D) at high/middle management levels.

The examination of the innovation barriers/challenges in the new foods industry (i.e. novelty of innovation, need for reconfiguration, visibility of innovation and 'appropriability' of innovation) provided some guidance to predict how local/regional strategic choices may drive balanced design approaches (structural separation, parallel structures) during the next period. A key conclusion arising from this research is that the rapid pace of change in the food industry requires companies from both countries to be agile, flexible and eager to continuously rely on innovation or imitation, by case. Italian and Romanian food companies should drive consumers' propensity by designing functional foods close to traditional recipes in order to gain not only functional assets (health reward and technological risk acceptance) but also emotional character (familiarity and heritage). Re-designing the traditional food by adding bio-active ingredients could become a key field in the agri-food business, able to provide long term solutions to the actual agro-alimentary global challenges.

This study also revealed the necessity for a higher level of technological transfer and lower innovation costs in the EU agri-food business. It also showed the need to increase the responsibility of companies' stakeholders and their awareness about the new technologies impact on public health.

This research focused on various specific operational aspects of $R \& D$ and marketing functions from Italian and Romanian companies, provides the basis for a future intricate analysis at industry-level of the business strategic profiles/business models that are capable to drive the development of new foods in Europe. Further work is needed to explore the local strategies' effectiveness in Italy and Romania and also to explain through a quantitative study the international patterns of innovation and dynamics in the functional food industry.

\section{Acknowledgment}

This article is a result of the project POSDRU/88/1.5./S/55287 „Doctoral Programme in Economics at European Knowledge Standards (DOESEC)". This project is co-funded by the European Social Fund through The Sectorial Operational Programme for Human Resources Development 2007-2013, coordinated by The Bucharest Academy of Economic Studies in partnership with West University of Timisoara.

\section{References}

Annunziata, A. \& Vecchio R. (2011). "Functional Foods Development in the European Market: A Consumer Perspective," Journal of Functional Foods, 3 (3), 223-228.

Bartlett, C. A. \& Ghoshal, S. (1998). Managing Across Borders: the Transnational Solution. (Second Ed.). Harvard Business School Press, Boston, MA.

Brambilla, G. \& Martelli, A. (2007). "Genotoxic and Carcinogenic Risk to Humans of Drug-Nitrite Interaction Products," Mutation Research, 635 (1), 17-52.

Broman, G., Holmberg, J. \& Robèrt, K.- H. (2000). "Simplicity Without Reduction: Thinking Upstream Towards the Sustainable Society," Interfaces, 30 (3), 13-25.

Chathotha, P. K. \& Olsenb, M. D. (2007). “Does Corporate Growth Really Matter in the Restaurant Industry?," Hospitality Management, 26, 66-80. 
Chiru, C. (2009). 'Have Marketing and R\&D Become a Threat for Consumer Health? the Case of the Romanian Soft Drinks Market,' Proceedings of the 16th International Conference on Chemistry and Chemical Engineering, (RICCCE 16), ISBN 978-606521-349-4, September 2009, Sinaia, Romania.

Chiru, C. (2011). 'Go Local Corporate Strategy and Functional Foods Development,' Proceedings of the 1st Organisational Governance Conference Corporate Governance Crises: Causes, Effects and Solutions, ISBN: 978-185-721-412-3, 15 - 16 September 2011, De Montfort University, Leicester, UK.

Coveney, J. (2005). Food, Morals and Meaning: the Pleasure and Anxiety of Eating, (2nd Ed)., London and New York, Routledge, Taylor and Francis Group.

Dehnen-Schmutz, K., Holdenrieder, O., Jeger, M. J. \& Pautasso, M. (2010). "Structural Change in the International Horticultural Industry: Some Implications for Plant Health," Scientia Horticulturae, 125 (1), 1-15.

Diplock, A. T., Agget, P. J., Ashwel, M., Bornet, F., Fern, E. B. \& Roberfroid, M. B. (1999). "Scientific Concepts of Functional Foods in Europe: Consensus Document," British Journal of Nutrition, 81 (4), 1-27.

Duffy, R. \& Fearne, A. (2007). Partnerships and Alliances in UK Supermarket Supply Networks, Food Supply Chain Management, Bourlakis, M.A., Weightmanp, P.W.H., (Ed.), Blackwell Publishing Ltd., 136-152.

Ehrenberg, A., Barnard, N. \& Sharp, B. (2000). "Problems with Marketing's 'Decision' Models," Visionary Marketing for the 21st Century: Facing the Challenge, Australian \& New Zealand Marketing Academy Conference Proceedings, 1520-1524.

Elango, B. (2004). "Geographic Scope of Operations By Multinational Companies: an Exploratory Study of Regional and Global
Strategies," European Management Journal, 22 (4), 431-441.

Frewer, L., Scholderer, J. \& Lambert, N. (2003). "Consumer Acceptance of Functional Foods: Issues for the Future," British Food Journal, 105 (10), 714-731.

Gugler, K., Mueller, D. C. \& Yurtoglu, B. B. (2004). "Corporate Governance and the Returns on Investment," Journal of Law and Economics, 47 (2), 598-633.

Harris-Roxas, B. \& Harris, E. (2011). "Differing Forms, Differing Purposes: a Typology of Health Impact Assessment," Environmental Impact Assessment Review, 31, 396-403.

Johns, T. \& Eyzaguirre, P. B. (2007). "Biofortification, Biodiversity and Diet: a Search for Complementary Applications Against Poverty and Malnutrition," Food Policy, 32, 1-24.

Johns, T., Sthapit, B. R. (2004). “Biocultural Diversity in the Sustainability of Developing Country Food Systems," Food and Nutrition Bulletin, 25, 143-155.

Kotler, P. (2000). Marketing Management : the millennium edition, 10th Edition, Prentice Hall, New Jersey, P.5.

Kotler, P. (1999). 'Principles of Marketing, 2nd European Edition,' Prentice Hall Europe, P. 607.

Lappalainen, R., Kearney, J. \& Gibney, M. (1998). "A Pan-EU Survey of Consumer Attitudes to Food, Nutrition and Health: an Overview," Food Quality and Preference, 9 (6), 467-478.

Margetts, B. M., Martinez, J. A., Saba, A., Holm, L. \& Kearney, M. (1997). "Definitions of 'Healthy' Eating: a Pan-EU Survey of Consumer Attitudes to Food, Nutrition and Health," European Journal of Clinical Nutrition, 51 (2), S23-S29. 
Mcintyre, L. \& Rondeau, K. (2011). "Individual Consumer Food Localism: a Review Anchored in Canadian Farmwomen's Reflections," Journal of Rural Studies, 27, 116124.

Niva, M. (2007). "All Foods Affect Health: Understandings of Functional Foods and Healthy Eating Among Health-Oriented Finns," Appetite, 48 (3), 384-393.

Raisch, S. (2008). "Balanced Structures: Designing Organizations for Profitable Growth," Long Range Planning, 41, 483-508.

Rao, M. (2005). Knowledge Management Tools and Techniques, Practitioners and Experts Evaluate KM Solutions, ButterworthHeinemann, P 193.

Richardson, N. J., Macfie, H. J. H. \& Shepherd, R. (1994). "Consumer Attitudes to Meat Eating," Meat Science, 36, 57-65.

Rugman, A. M. \& Verbeke, A. (2004). "A Perspective on the Regional and Global Strategies of Multinational Enterprises," Journal of International Business Studies, 35(1), 3-18.

Rugman, A. M. \& Verbeke, A. (2008). “A Regional Solution to the Strategy and Structure of Multinationals," European Management Journal, 26, 305- 313.

Sen, A. (2004). Why Health Equity? Public Health, Ethics and Equity, Anand S, Peter F, Sen A, (Ed). New York: Oxford University Press, 21-34.

Shepherd, R. (1990). 'Factors Influencing Food Preferences and Choice,' Handbook of the Psychophysiology of Human Eating, Shepherd, R. (Ed.), (1st Ed). 3-24), Chichester, John Wiley \& Sons Ltd.

Stroia, A. \& Chiru, C. (2010). 'Traditionalism and Functionality in the Romanian Cuisine,' Quality-Access to Success, 116 (2), 1234-1241.
Tylecote, A. \& Ramirez, P. (2006). “Corporate Governance and Innovation: the UK Compared with the US and 'Insider' Economies," Research Policy, 35, 160-180.

Urala, N. \& Laahteenmaaki, L. (2004). "Attitudes Behind Consumers' Willingness to Use Functional Foods," Food Quality and Preference, 15 (7-8), 793-803.

Ward, M. H., Pan, W.-H., Cheng, Y.-J., Li, F.-H., Brinton, L. A., Chen, C.-J., Hsu, M.-M., Chen, I.H., Levine, P. H. \& Yang, C.-S. (2000). “Dietary Exposure to Nitrite and Nitrosamines and Risk of Nasopharyngeal Carcinoma in Taiwan," International Journal of Cancer, 86 (5), 603-609.

Willard, B. (2005). The Next Sustainability Wave: Building Boardroom Buy-in. Gabriola Island, B.C.: New Society Publishers. 